\title{
Editorial
}

\section{In memoriam of a prominent composer of the Bcl-2 family symphony}

\author{
C Borner ${ }^{*, 1}$ \\ ${ }^{1}$ Institute of Molecular Medicine and Cell Research, Albert Ludwigs University of \\ Freiburg, Freiburg, Germany \\ * Corresponding author: C Borner, Institute of Molecular Medicine and Cell \\ Research, Albert Ludwigs University of Freiburg, Stefan Meier Strasse 17, D- \\ 79104 Freiburg, Germany. Tel: + 49761203 9618; Fax: + 49761203 9620; \\ E-mail: christoph.borner@uniklinik-freiburg.de
}

Cell Death and Differentiation (2006) 13, 1248-1249.

doi:10.1038/sj.cdd.4401998

This review series honours Stanley J Korsmeyer, a great man, superb mentor and dedicated cancer and apoptosis biologist who largely contributed to the findings, concepts and models about apoptosis regulation by $\mathrm{Bcl}-2$ family members, which you are going to read here. It is not my intention to summarize all his achievements as this has been done in many obituaries since his death on March 31, 2005, ${ }^{1-3}$ and each Review and News and Commentary in this series again contains acknowledgements, tributes and personal notes for him. I just want to focus on some highlights in the partition of the Bcl-2 family symphony that Stan helped to compose together with other research groups.

When I started my apoptosis career in 1991, there was not much known about Bcl-2. Seven years before, Tsujimoto et al. ${ }^{4}$ in Carlo Croce's lab cloned the $t(14 ; 18)$ chromosomal breakpoint of neoplastic $B$ cells and identified the gene locus on chromosome 18 as bcl-2. The same group ${ }^{5}$ and the team of Michael Cleary and Jeffrey Sklar ${ }^{6}$ subsequently sequenced the bcl-2 gene and proposed that levels of Bcl-2 expression may be higher in B-cell lymphomas. Stan Korsmeyer's group ${ }^{7}$ cloned the breakpoint as well, started to overexpress $\mathrm{Bcl}-2$ and demonstrated in 1989 that $\mathrm{Bcl}-2$ immunoglobulin transgenic mice extended B-cell survival and follicular lymphoproliferation. Just a year before in 1988, David Vaux, Suzanne Cory and Jerry Adams ${ }^{8}$ published the breathtaking news that $\mathrm{Bcl}-2$ functioned as the first oncogene to enhance cell survival rather than cell proliferation. Many of us were fascinated to find out how Bcl-2, the only member of the family known at that time, would perform such a novel action and contribute to neoplasia via an antiapoptotic function. In 1990, Korsmeyer's group ${ }^{9}$ reported a localization of $\mathrm{Bcl}-2$ to the inner mitochondrial membrane. Although we know now that $\mathrm{Bcl}-2$ does not localize there but rather resides in the outer mitochondrial and nuclear/endoplasmic reticulum membranes, this paper proposed for the first time a potential mitochondrial function of $\mathrm{Bcl}-2$. Vaux et al. ${ }^{10}$ then demonstrated 2 years later that $\mathrm{Bcl}-2$ acted like its nematodal homologue CED-9, that is, upstream of CED-4/CED-3 to block the activation of the CED-3 caspase. Thus, the race was on to decipher the exact mechanism by which Bcl-2 controlled mitochondrial function and caspase activation in mammals. Note that it was only at the end of 1993 when the first mammalian caspase, ICE/caspase-1, was reported to be homologous to nematodal CED-3, ${ }^{11}$ and we did not even think in our wildest dreams that mitochondria would be so important for apoptosis regulation in mammals.

But this changed quite rapidly. In 1993, Stan's group ${ }^{12}$ knocked-out $\mathrm{Bcl}-2$ in mice and found that the animals were astonishingly viable but exhibited fulminant lymphocyte apoptosis, premature aging and polycystic kidney disease. This indicated that Bcl-2 was not the only member of its kind to regulate apoptosis during embryonic development and tissue/ cell turnover. In 1987, Pearson et al. ${ }^{13}$ already discovered that the BHRF1 protein from Epstein-Barr virus had extensive sequence homology to Bcl-2 and proposed that the virus could use this potentially antiapoptotic protein to sustain the survival of host cells during progeny production (for an update on viral homologues, see reviews by Marie Hardwick and Eileen White). However, it was not yet clear if additional homologues of $\mathrm{Bcl}-2$ were needed for apoptosis regulation in mammals. In 1993, Lawrence Boise ${ }^{14}$ in Craig Thompson's lab reported such a homologue in Cell and dubbed it Bcl- $\mathrm{x}_{\mathrm{L}}$. In the same issue, Zoltan Oltvai ${ }^{15}$ in Stan Korsmeyer's lab unveiled the first $\mathrm{Bcl}-2$-binding partner, Bax, and showed that it was also a $\mathrm{Bcl}-2$ homologue but with proapoptotic activity. This led to the famous Korsmeyer rheostat model, which says that Bax-like and Bcl-2-like proteins bind to and neutralize each other, and depending on the amount of each partner, the cells will survive or die. ${ }^{16}$ Unfortunately, this model did not solve the chicken/egg question of whose activity is held in check by whom, so that additional signalling molecules were proposed to regulate the heterodimerization of $\mathrm{Bcl}-2$ and Bax.

We all know that from then on the apoptosis field literally exploded with the identification of additional anti- and proapoptotic members of the $\mathrm{Bcl}-2$ family, a series of caspases and their inhibitors (IAPs), the CED-4 homologue Apaf-1 and the mitochondrial pathway (all reviewed in this series). The discovery of the BH3-only proteins, which share only the BH3-domain with the multidomain-containing Bcl-2 and Bax subfamilies, was a landmark to explain the missing link between the sensing/activating and execution (mitochondrial membrane perforation, caspase activation) steps of apoptosis controlled by Bcl-2 family members. This also made sense from an evolutionary point of view, as the trigger for programmed cell death in the nematode turned out to be the BH3-only protein EGL-1, which displaced the CED-3 activator CED-4 from the Bcl-2 homologue CED-9. ${ }^{17}$ Stan Korsmeyer's group identified the first mammalian $\mathrm{BH} 3$-only proteins $\mathrm{Bid}^{18}$ and $\mathrm{Bad}^{19}$ (although in the latter no BH3 domain, but $\mathrm{BH} 1$ and $\mathrm{BH} 2$ domains were initially detected), but could not explain at that time how these proteins impinged on Bcl-2- and Bax-like factors. Do we know today? Well, for almost a decade we 
have been arguing at each apoptosis conference and in numerous reviews (including in the present series) whether some $\mathrm{BH} 3$ only proteins (such as Bim, Bid or Puma) directly activate Bax and Bak by a kiss-and-run-away paradigm or whether all these proteins are in high-affinity love with $\mathrm{Bcl}-2$ survival factors ${ }^{20}$ and as a consequence chase off Baxand Bak-, or some Bax/Bak-activating factors, which were previously bound. Stan would have liked to enter into this sort of discussion as his group was among those who proposed 'activator' (directly acting on Bax/Bak) and 'derepressor' (acting via $\mathrm{Bcl}-2$-like factors) subspecies of $\mathrm{BH}$-only proteins ${ }^{21}$ (for further discussions on this subject, see the reviews by David Huang and Andreas Villunger, in this issue).

The Bcl-2 symphony became even more pompous by the discovery that its members may have additional functions to apoptosis. Spurred by an initial observation by Mary Collins' group, ${ }^{22}$ several groups including Stan's found that Bcl-2 and its homologues had a cell cycle inhibitory function separable from its enhancement of cell survival ${ }^{23-26}$ (for an update see the review by Elizabeth Yang/Atan Gross, in this issue). Just before Stan's death, his group identified novel binding partners of Bad on mitochondria, ${ }^{27}$ among which one enzyme, called glucokinase, proved to be involved in glucose metabolism. This supported a link between apoptosis and metabolism that was previously suggested by Craig Thompson's group ${ }^{28}$ (see his review, in this issue).

Stanley Korsmeyer was not only devoted to basic science. He was a cancer biologist and wanted to see his achievements applied in the clinic. Thus, the potential use of $\mathrm{BH} 3$ mimetics to disrupt the Bcl-2 survival complex and/or activate Bax/Bak and kill chemoresistant tumour cells did not escape his eyes. Concomitant with other research groups, he developed stabilized alpha helical $\mathrm{BH} 3$ domains (hydrocarbon-stapled), which proved to be protease-resistant and cell-permeable, bound with increased affinity to Bcl-2-like proteins and effectively killed leukaemia cells in vitro and in human leukaemia xenografts in vivo. ${ }^{29}$ The recent advances in this field will be discussed in this issue by Timothy McDonnell, Loren Walensky and John Reed (letter to the editor).

We have chosen the various topics in this review series to present a snapshot about where we stand with the Bcl-2 family symphony today, after the first note was composed 22 years ago. I think that the piece is fascinating enough to be played to a wide audience! But it still requires fine-tuning and it exhibits disharmony in some parts. This involves the mechanisms by which BH3-only proteins dance with the Bcl-2- and Bax-like factors as well as how Bax and Bak really perforate the mitochondrial membrane and how cytochrome $c$ or other apoptogenic factors are released to orchestrate caspases or other downstream players of the apoptosis requiem (see reviews by Doug Green, Gordon Shore, Kathleen Kinnally and Paolo Bernardi, in this issue). For example, how does the symphony play if Bax and Bak or the apoptosome are missing or mitochondria are prevented from fusing or fissioning (a novel theme summarized by Jean-Claude Martinou/Richard Youle and Barbara Conradt)? Are mitochondria indeed important for the beat of the symphony or are they just the drums and trumpets that add the fortissimo or accelerate the rhythm? Many of these questions remain. So, as with Beethoven's 9th, the Bcl-2 family symphony is yet unfinished and we are all committed to complete it, with our own style and composition, but with Stan's creativity, accuracy and sense of orchestration and harmony on our minds and in our hearts.

1. Thompson C (2005) Cell 21: 319-320.

2. Horvitz HR (2005) Nature 435: 161.

3. Hess JL (2005) Nat. Cell Biol. 7: 556.

4. Tsujimoto $Y$ et al. (1984) Science 226: 1097-1099.

5. Tsujimoto $Y$ et al. (1985) Science 229: 1390-1393.

6. Cleary ML et al. (1986) Cell 47: 19-28.

7. McDonnell TJ et al. (1989) Cell 57: 79-88.

8. Vaux DL et al. (1988) Nature 335: 440-442.

9. Hockenbery D et al. (1990) Nature 348: 334-336.

10. Vaux DL et al. (1992) Science 258: 1955-1957.

11. Miura M et al. (1993) Cell 75: 653-660.

12. Veis DJ et al. (1993) Cell 75: 229-240.

13. Pearson GR et al. (1987) Virology 160: 151-161.

14. Boise LH et al. (1993) Cell 74: 597-608.

15. Oltvai ZN et al. (1993) Cell 74: 609-619.

16. Korsmeyer SJ et al. (1993) Semin. Cancer Biol. 4: 327-332.

17. Conradt B and Horvitz HR (1998) Cell 93: 519-529.

18. Wang K et al. (1996) Genes Dev. 10: 2859-2869.

19. Yang E et al. (1995) Cell 80: 285-291.

20. Chen L et al. (2005) Mol. Cell 17: 393-403.

21. Letai A et al. (2002) Cancer Cell 2: 183-192.

22. Marvel J et al. (1994) Oncogene 9: 1117-1122.

23. Vairo $G$ et al. (1996) Oncogene 13: 1511-1519.

24. Linette GP et al. (1996) Proc. Natl. Acad. Sci. USA 93: 9545-9552.

25. Borner C (1996) J. Biol. Chem. 271: 12695-12698.

26. O'Reilly LA et al. (1996) EMBO J. 15: 6979-6990.

27. Danial NN et al. (2003) Nature 424: 952-956.

28. Vander Heiden MG et al. (1999) Mol. Cell 3: 159-167.

29. Walenskiy LD et al. (2004) Science 305: 1411-1413. 